\title{
Studies on In Vivo Formation of Nitroso Compounds (VII)
}

\author{
In Vitro Formation of Nitrite by Mixing Different Kinds of Foods
}

(Received April 26, 1976)

Hajimu IshIwATA

(National Institute of Hygienic Sciences: 18-1, Kamiyoga 1-chome, Setagaya-ku, Tokyo)

\begin{abstract}
In vitro formation of nitrite in the incubation mixture of some vegetables and natto was studied. When the mixture of Chinese cabbage-natto, radish-natto or spinach-natto was incubated at $37^{\circ} \mathrm{C}$ for $1-4 \mathrm{hr}$, the formation of nitrite was observed, and the maximum concentration of nitrite was more than $500 \mathrm{ppm}$. It was confirmed by the experiment using sodium nitrate and Bacillus natto, a nitrate-reducing bacterium, isolated from natto that nitrite in the incubation mixtures was formed from nitrate in vegetables by $B$. natto in natto. These results suggest that nitrite, a precursor of carcinogenic nitroso compounds, may be formed in digestive canal when different kinds of foods containing nitrate and nitrate-reducing microorganisms separately were taken at the same time.
\end{abstract}

\section{Introduction}

The nitroso compounds, a group of potent carcinogens which induce tumors in various organs of laboratory animals, are produced by the reaction of nitrite with secondary amines or with other amino compounds.

The main sources of nitrite, one of the precursors of nitroso compounds, for human body are considered as follows. a) Sodium nitrite (as food additive): Sodium nitrite has been used for meat products as a color fixative, and the residual amount of nitrite in these products is restricted less than $70 \mathrm{ppm}$ in Japan. ${ }^{1)}$ b) Vegetables: Fresh and salted vegetables contain 0-5 ppm and 10-20 ppm of nitrite, ${ }^{2), 3)}$ respectively. c) Saliva: Human saliva contains a significant amount of nitrite. ${ }^{4)}$ The concentration of salivary nitrite is dependent on the nitrate content in the foods ingested. ${ }^{5)}$

On the other hand, since nitrite is easily produced from nitrate by the action of microorganisms, it may be formed in digestive canal when different kinds of foods containing nitrate and nitrate-reducing microorganisms separately are taken at the same time.

Therefore, in vitro formation of nitrite in the incubation mixtures of some vegetables contain- ing high concentration of nitrate and natto, a boiled soybean product fermented by Bacillus natto, was studied. Such a combination of foods is thought to be suitable for the purpose of this study, because natto contains a lot of $B$. natto which is a kind of nitrate-reducing bacterium and vegetables such as Chinese cabbage are good sources of nitrate.

\section{Experimental methods}

\section{1 Foods tested}

The contents of nitrite and nitrate, and number of microorganisms in the foods used in this experiments were shown in Table 1. These foods were purchased from markets. The number of microorganisms in the foods was calculated from the number of colonies on a brain heart infusion (BHI, Difco Lab.) agar plate which was incubated at $37^{\circ} \mathrm{C}$ for $48 \mathrm{hr}$ after inoculation of a diluted solution obtained from test foods. Thus, the number of microorganisms shown in Table 1 included various microorganisms other than nitrate-reducing bacteria.

\section{2 Isolation of $B$. natto}

Five grams of natto were suspended in $50 \mathrm{ml}$ of a $0.85 \%$ sodium chloride solution. After the suspension was heated at $70^{\circ} \mathrm{C}$ for $20 \mathrm{~min}$, the suspension was spread on a BHI agar plate. 
Table 1. Contents of Nitrite and Nitrate and the Number of Microorganisms in the Foods Tested

\begin{tabular}{lccc} 
Food & Nitrite* & Nitrate* & Microorganisms** \\
\hline Chinese cabbage & N. D. & 3037 & $1 \times 10^{8}$ \\
Salted Chinese cabbage & 29.1 & 1604 & $1 \times 10^{6}$ \\
Celery & N. D. & 1163 & $1 \times 10^{5}$ \\
Spinach & N. D. & 2465 & $2 \times 10^{6}$ \\
Radish & N. D. & 3606 & $2 \times 10^{4}$ \\
Natto & N. D. & 19 & $6 \times 10^{9}$ \\
$*$ ppm & & & \\
$* *$ cells/g & &
\end{tabular}

Selective culture was repeated for several times to obtain $B$. natto.

The isolated strain was gram-stain positive, rod-shaped, endospore-forming, gas negative and biotin requiring. These properties coincided with those of $B$. natto described by Kida et. al ${ }^{6}{ }^{6}$

\section{3 Formation of nitrite}

1) Formation by mixing vegetables with natto Chinese cabbage, radish, spinach and celery were used as the source of nitrate. These vegetables were treated by a juicer, and the juices obtained were used for the experiments. Fifty grams of natto was homogenized with $50 \mathrm{~g}$ of the vegetable juice by a waring blender for $1 \mathrm{~min}$, and the homogenate was incubated at $37^{\circ} \mathrm{C}$ with shaking. Nitrite and nitrate were determined at definite intervals. Natto autoclaved at $121^{\circ} \mathrm{C}$ for $15 \mathrm{~min}$ was used as the reference.

2) Formation by mixing vegetables with $B$. natto

$B$. natto was cultured overnight with $\mathrm{BHI}$ and collected by centrifugation (3000 rpm, $10 \mathrm{~min}$ ). The cells collected were suspended again into BHI $\left(8.9 \times 10^{6}\right.$ cells $\left./ \mathrm{ml}\right)$. The mixture of $10 \mathrm{ml}$ of the cell suspension and $10 \mathrm{ml}$ of a $1000 \mathrm{ppm}$ sodium nitrate solution or vegetable juice was incubated at $37^{\circ} \mathrm{C}$. Nitrite and nitrate were determined at definite intervals.

Determinations of nitrite and nitrate were performed by the method described previously. ${ }^{7)}$

\section{Results and Discussion}

\section{1 Formation of nitrite by mixing vegetables with natto}

Time-course of nitrite formation by the combination of Chinese cabbage-natto, radish-natto, spinach-natto or spinach-salted Chinese cabbage was shown in Fig. 1-4. The initial concentrations of nitrate in the mixtures were $1329 \mathrm{ppm}$, $1744 \mathrm{ppm}, 1318 \mathrm{ppm}$ and $1849 \mathrm{ppm}$, respectively. In the case of Chinese cabbage-natto (Fig. 1),

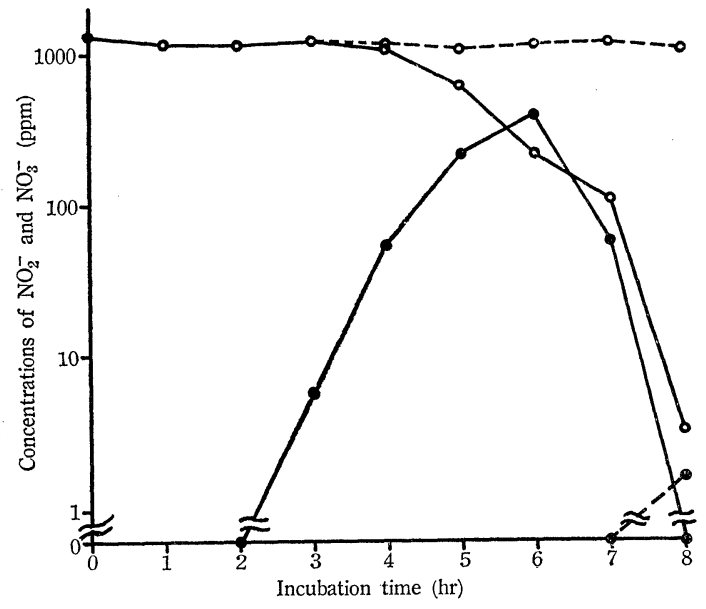

Fig. 1. Formation of nitrite by mixing Chinese cabbage with natto.

-, nitrite; $\bigcirc$, nitrate; - Chinese cabbage plus natto; -.--, Chinese cabbage plus autoclaved natto.

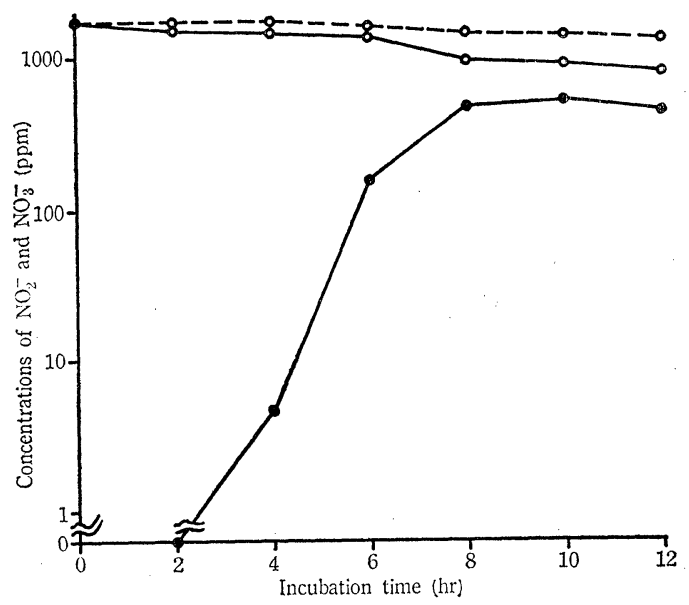

Fig. 2. Formation of nitrite by mixing radish with natto.

- nitrite; $\bigcirc$, nitrate; - , radish plus natto; --.-, radish plus autoclaved natto. 


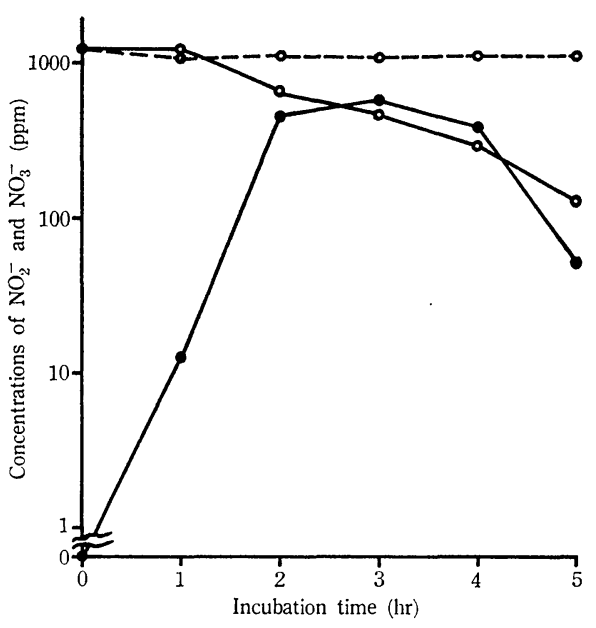

Fig. 3. Formation of nitrite by mixing spinach with natto.

○, nitrite; $\bigcirc$, nitrate; $\longrightarrow$, spinach plus natto; -..-, spinach plus autoclaved natto.

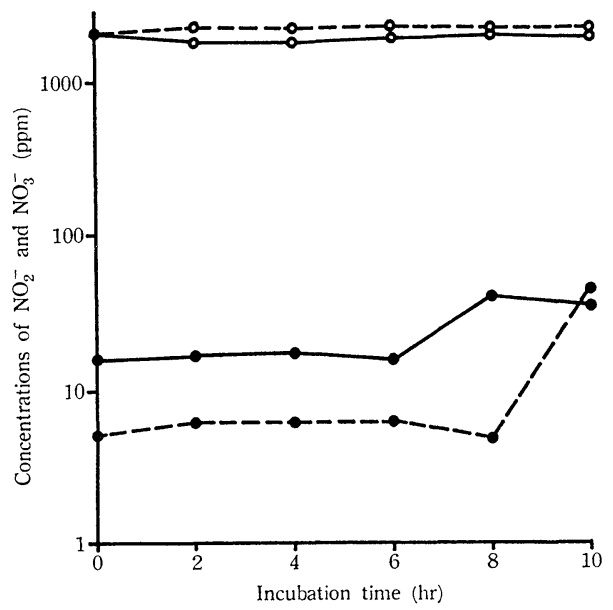

Fig. 4. Formation of nitrite by mixing spinach with salted Chinese cabbage.

○, nitrite; $\bigcirc$, nitrate; —_, spinach plus salted Chinese cabbage; - -.., spinach plus autoclaved salted Chinese cabbage.

$388 \mathrm{ppm}$ of nitrite was formed $6 \mathrm{hr}$ after incubation. The concentration of nitrate decreased rapidly after $4 \mathrm{hr}$ and the residual nitrate was $3.7 \mathrm{ppm}$ and no nitrite was detected after $8 \mathrm{hr}$. On the other hand, when autoclaved natto was incubated with Chinese cabbage, nitrite was not detected and the nitrate concentration was not changed after $7 \mathrm{hr}$. In the case of radish-natto (Fig. 2), 509 ppm of nitrite was formed after 8 hr. When autoclaved natto was incubated with radish, however, nitrite was not detected in the experimental period. In the case of spinachnatto (Fig. 3), the maximum concentration of nitrite $(609 \mathrm{ppm})$ was detected after $3 \mathrm{hr}$. In the case of spinach-salted Chinese cabbage, salted Chinese cabbage was used as a source of nitratereducing microorganisms instead of natto. In this case, $16 \mathrm{ppm}$ of nitrite which existed in original salted Chinese cabbage was detected at the initial time. The concentration of nitrite did not change up to $6 \mathrm{hr}$ and then increased to 42 ppm after $8 \mathrm{hr}$ (Fig. 4).

The decrease of nitrate which was comparable to the increment of nitrite was observed in the mixture of radish-natto or spinach-natto as the case of Chinese cabbage-natto.

The increase of nitrite in the incubation: mixtures of vegetables and natto may be due to the co-existence of nitrate in vegetables and nitrate-reducing microorganisms, especially $B$. natto in natto. Since the vegetables used in the experiments were not germ-free, the increase of nitrite was also observed in the incubation mixture of autoclaved natto and vegetables after long-term incubation.

3. 2 Formation of nitrite by mixing vegetables: with $B$. natto

To make clear the above-mentioned phenomenon, the change of nitrite was determined at different intervals after mixing Chinese cabbage

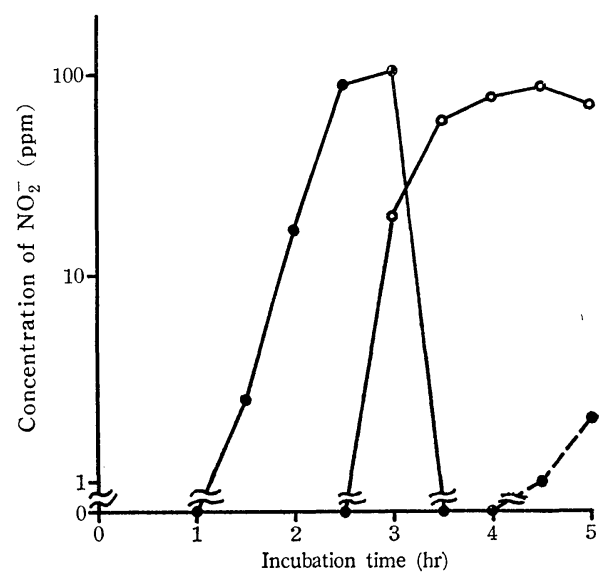

Fig. 5. Formation of nitrite by mixing celery or Chinese cabbage with $B$. natto.

- - nitrite, celery plus $B$. natto; ---O, nitrite, celery plus autoclaved BHI solution; $\bigcirc-\bigcirc$, nitrite, Chinese cabbage plus $B$. natto. 
or celery with $B$. natto isolated from natto. The results were shown in Fig. 5 .

In the case of celery- $B$. natto, nitrite was detected after $1.5 \mathrm{hr}$, and then increased up to $106 \mathrm{ppm}$ after $3 \mathrm{hr}$. However, when an autoclaved $3.7 \%$ BHI solution was used instead of the suspension of $B$. natto, nitrite was also detected after $4.5 \mathrm{hr}$. In the case of Chinese cabbage$B$. natto, the maximum concentration of nitrite (84 ppm) was observed after $4.5 \mathrm{hr}$, but nitrite was not detected in Chinese cabbage-autoclaved $3.7 \% \mathrm{BHI}$ solution during the incubation.

These results appear to indicate that one of the cause of nitrite formation is due to the action of $B$. natto, but nitrate-reducing microorganisms originated in vegetables also formed nitrite after long-term incubation, as shown in Fig. 1.

\section{3 Formation of nitrite by mixing sodium nitrate with $B$. natto}

From the results described above, it was presumed that nitrite produced in the incubation mixture of vegetables and natto should be formed from nitrate by the nitrate-reducing activity of $B$. natto. Therefore, the nitrite formation was determined in a pure system which was composed of sodium nitrate and $B$. natto. Nitrite was found distinctly to be formed in this system (Fig. 6). This result suggested that nitrite

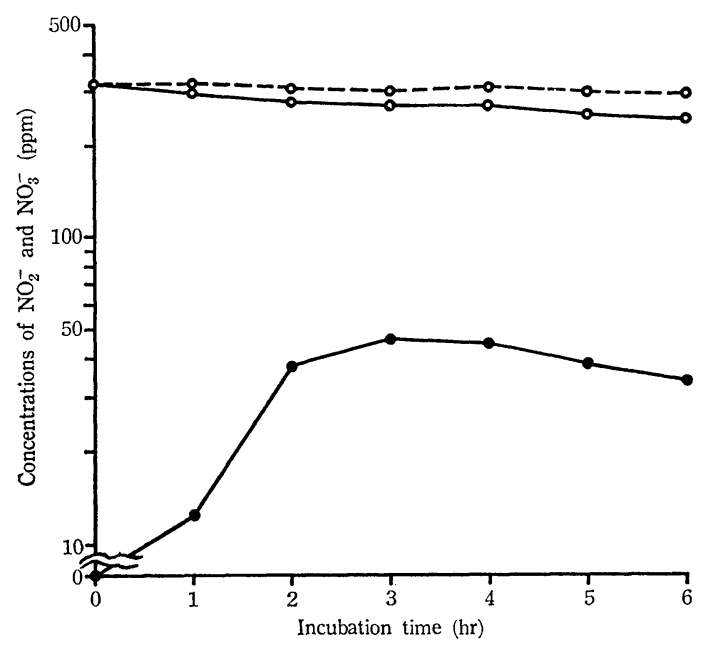

- Fig. 6. Formation of nitrite from sodium nitrate and $B$. natto.

- nitrite; $\bigcirc$, nitrate; $\longrightarrow$, sodium nitrate solution plus $B$. natto; ----, sodium nitrate solution.

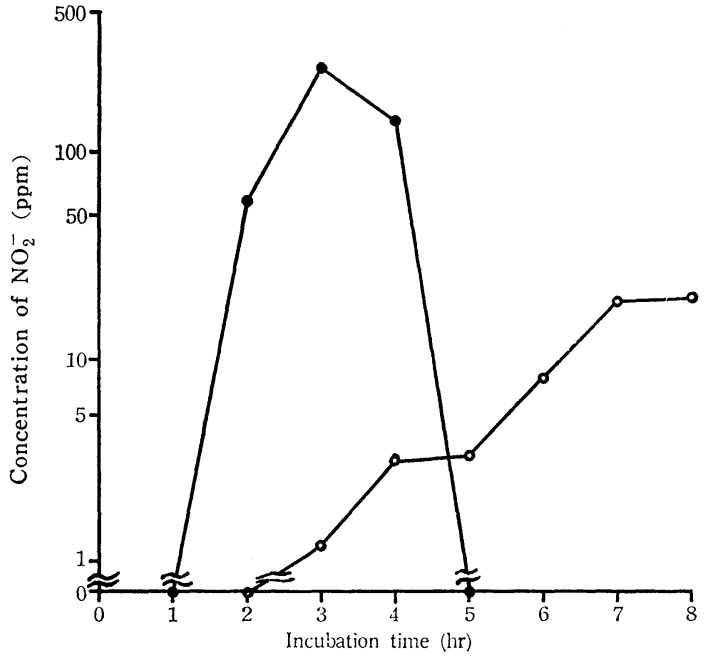

Fig. 7. Effect of $\mathrm{pH}$ on the formation of nitrite by mixing Chinese cabbage with natto.

- nitrite, $\mathrm{pH} 7.0$; $\bigcirc$, nitrite, $\mathrm{pH} 5.0$.

Nitrite was not detected for $24 \mathrm{hr}$-incubation when the mixture was adjusted to $\mathrm{pH} 3.0$ and 1.0 .

might be formed from nitrate in vegetables by $B$. natto in natto when the mixture of vegetable and natto was incubated.

\section{4 Effect of $\mathrm{pH}$ on nitrite formation}

The $\mathrm{pH}$ of the mixture of Chinese cabbage and natto was adjusted to $1,3,5$, and 7 with hydrochloric acid and made up to $150 \mathrm{ml}$ with water.

Formation of nitrite was shown in Fig. 7. In the case of $\mathrm{pH} \mathrm{7,} \mathrm{the} \mathrm{formation} \mathrm{of} \mathrm{nitrite} \mathrm{was}$ the same as the result shown in Fig. 1. At pH $5,1.2 \mathrm{ppm}$ of nitrite was formed after $3 \mathrm{hr}$, and the concentration increased to $16.0 \mathrm{ppm} 8 \mathrm{hr}$ after incubation. No nitrite was detected in the case of $\mathrm{pH} 3$ and 1 . These results indicate that nitrite may not be formed in normal human stomach, but forms in the stomach when a lot of foods is present in it or the stomach function decreases.

3.5 Effect of temperature on nitrite formation

All the experiments described above were performed at $37^{\circ} \mathrm{C}$, supposing the formation in digestive canal. Although the nitrite formation may occur at room temperature, the incubation at $30^{\circ} \mathrm{C}$ and $5^{\circ} \mathrm{C}$ was also carried out using Chinese cabbage and natto. The incubation mixture was divided into 3 portions for $37^{\circ} \mathrm{C}$-, 


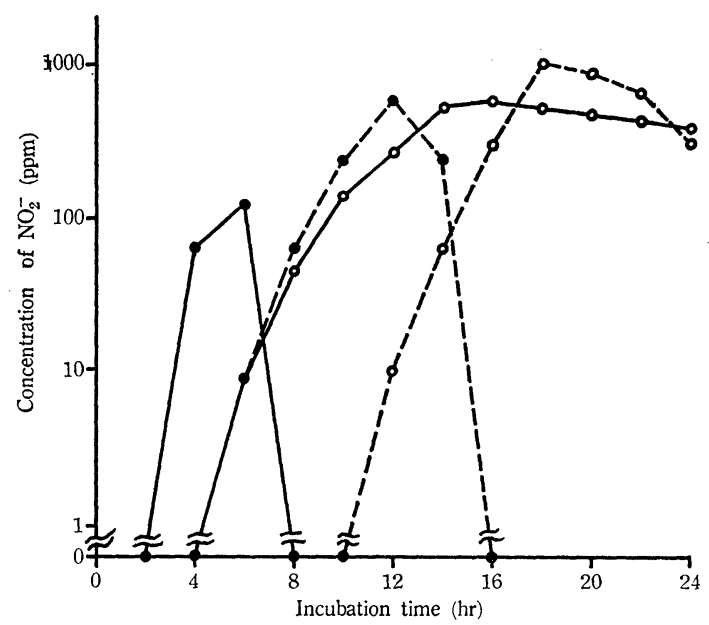

Fig. 8. Effect of temperature on the formation of nitrite by mixing Chinese cabbage with natto.

- nitrite, incubated at $37^{\circ} \mathrm{C} ; \bigcirc$, nitrite, incubated at $30^{\circ} \mathrm{C}$; - Chinese cabbage plus natto; --.-, Chinese cabbage plus autoclaved natto.

Nitrite was not detected for $24 \mathrm{hr}$ when the mixture was incubated at $5^{\circ} \mathrm{C}$.

$30^{\circ} \mathrm{C}$-, and $5^{\circ} \mathrm{C}$-incubation. The results were shown in Fig. 8.

Larger amount of nitrite was formed in the mixture of Chinese cabbage and natto at $30^{\circ} \mathrm{C}$ than at $37^{\circ} \mathrm{C}$, especially when autoclaved natto was used. Nitrite accumulating ability of microorganisms existing in Chinese cabbage may be higher than that of $B$. natto. The results of $30^{\circ} \mathrm{C}$-incubation will be reported in next paper.

\section{Conclusion}

The experiments detecting the possible source of nitrite which is one of the precursor of carcinogenic nitroso compounds were ferformed, and the following results were obtained.

1) Over $500 \mathrm{ppm}$ of nitrite was detected in the mixture of various vegetables and natto by short term incubation.

2) Nitrite was also detected in the incubation mixture of vegetables and $B$. natto isolated from natto.

3) The formation of nitrite was observed when the mixture was adjusted to $\mathrm{pH} 5$ or 7 , or incubated at $37^{\circ} \mathrm{C}$ or $30^{\circ} \mathrm{C}$.

These results indicate that significant amounts of nitrite are produced when vegetables which contain a large amount of nitrate are mixed with some kinds of food such as natto which contain a lot of nitrate-reducing microorganisms.

\section{Acknowledgments}

The author is indebted to Dr. M. Ishidate, Tokyo Biochemical Research Institute, and Pr. T. Murata, Shizuoka College of Pharmacy, for their encouragements. This work was supported by Cancer Research Funds (1975) from the Ministry of Health and Welfare, Scientific Research Funds (1975) from the Ministry of Education, Science and Culture, and Special Research Funds (1975) from National Institute of Hygienic Sciences, and was co-worked with Dr. A. Tanimura and Miss Ito, National Institute of Hygienic Sciences.

\section{References}

1) The Ministry of Health and Welfare: "The Japanese Standards of Food Additives, 3rd edition" p. 26 (1974).

2) Harada, M., Nakamura, Y., Tanimura, A.: J. Food Hyg. Soc. Japan, 13, 36 (1972).

3) Siciliano, J., Krulick, S., Heisler, E. G., Schwartz, J.H., White, J.W.: J. Agric. Food Chem., 23, 461 (1975).

4) Tannenbaum, S.R., Sinskey, A.J., Weisman, M., Bishop, W.: J. Natl. Cancer Inst. 53, 79 (1974).

5) Ishiwata, H., Prakai, B., Nakamura, Y., Harada, M., Tanimura, A., Ishidate, M.: J. Food Hyg. Soc. Japan, 16, 19 (1975).

6) Kida, S., Hashida, S., Teramoto, S.: J. Ferment. Technol., 34, 542 (1956).

7) Harada, M., Ishiwata, H., Nakamura, Y., Tanimura, A., Ishidate, M.: J. Food Hyg. Soc. Japan, 16, 11 (1975). 